\title{
SABERES-FAZERES QUE ATRAVESSAM A EDUCAÇÃO DO CAMPO
}

\section{KNOWLEDGE-DOINGS THAT CROSS THE RURAL EDUCATION}

\section{SABERES-CONOCIMIENTOS QUE CRUZAN LA EDUCACIÓN $\boldsymbol{R} \boldsymbol{U} \boldsymbol{R} \boldsymbol{A L}$}

\author{
Isaura Isabel Conte ${ }^{1}$ \\ Universidade do Estado de Mato Grosso, Professora do Curso de Pedagogia do Campus de \\ Juara
}

\begin{abstract}
Marlene Ribeiro ${ }^{2}$
Universidade Federal do Rio Grande do Sul, Professora aposentada do Programa de PósGraduação em Educação (PPGEdu)
\end{abstract}

\begin{abstract}
Resumo: Neste texto abordam-se os saberes-fazeres, ou conhecimentos, de uma escola de educação do campo e alguns dilemas do contexto atual no desenvolvimento do processo pedagógico. As reflexões são oriundas de pesquisa participante, compreendendo estudos teóricos e intervenções empíricas. Utilizamo-nos de entrevistas gravadas e conversas direcionadas a docentes, funcionários técnicos e discentes, além de análise documental do PPP da escola. Enfatizamos que a formação dos profissionais atuantes na instituição merece ser pensada no contexto das escolas do campo, inclusive no que diz respeito ao acesso e à qualidade dessa formação. Há esforço pessoal por parte dos profissionais em relação às práticas, entretanto há questões que fogem ao seu alcance, inclusive no que se refere à saída dos jovens do campo por falta de políticas sociais como acesso à terra.
\end{abstract}

Palavras-chave: Educação do campo. Escola. Saberes-fazeres.

Abstract: In this text it was discussed the knowledge-doings, or knowledge, of a rural education school and some dilemmas of the current context in the development of the educational process. The ideas are from participant research, including theoretical and empirical interventions. We are relying on interviews recorded and conversations

\footnotetext{
${ }^{1}$ Pós-Doutora em Educação pela Universidade Federal do Rio Grande do Sul; Doutora em Educação pela Universidade Federal do Rio Grande do Sul.

${ }^{2}$ Pós-Doutora em Educação pela Universidade de Minas Gerais; Doutora em Educação em Educação pela Universidade de Minas Gerais.
} 
directed to teachers, technical staff and students, and documentary analysis of the school PPP. We emphasize that the training of professionals working in the institution deserves to be considered in the context of schools in the countryside, including with regard to access and quality of such training. There is personal effort on the part of professionals regarding the practice, however, there are issues beyond its scope, including with respect to the output of the rural youth by lack of social policies such as access to land.

Keywords: Rural education. School. Knowledge-doings.

Resumen: Nos acercamos de los saberes-conocimientos de una escuela de educación rural, en su contexto ctual y sus desafios de desarrollo en el proceso pedagógico. Las reflexiones surgen de la investigación participante, incluyendo estudios teóricos e intervenciones empíricos. Hacemos uso de entrevistas y conversaciones grabadas dirigidas a los profesores, estudiantes y profesionales técnicos, así como análisis documental de PPP escuela. Hacemos hincapié que la formación de los profesionales trabajadores de la institución merece ser considerada en el contexto de las escuelas en el campo, incluso en relación con el acceso y la calidad de dicha formación. Hay un esfuerzo personal por parte de los profesionales con respecto a la práctica, sin embargo, hay cuestiones más allá de su alcance, incluso con respecto a la salida del jóvenes del campo por falta de las politicas sociales, más bien, por aceso a la tierra. Palavras clave: Educación rural. Escuela. Saberes-conocimientos.

\section{INTRODUÇÃO}

Por meio deste artigo apresentamos algumas reflexões acerca dos saberes-fazeres de uma escola do campo situada no Município de Nossa Senhora do Livramento, no Estado do Mato Grosso. ${ }^{3} \mathrm{O}$ texto é oriundo de pesquisa empírica e teórica, e a abordagem dessa temática se torna relevante pelo fato de que, embora haja uma grande quantidade de produção científica relacionada à Educação do Campo (EdoC), de modo geral, trata-se de concepções e da defesa conceitual de um objeto em disputa, conforme analisa Caldart (2008). Do nosso ponto de vista, entretanto, são escassas as reflexões que tratam de como se processa essa modalidade específica de educação, sem ficar simplesmente no relato de experiências, ainda que isso seja de grande relevância, ou na defesa conceitual.

\footnotetext{
${ }^{3}$ Vamos tratar pelo nome de Livramento.
} 
O Município de Livramento, onde se situa a Escola investigada, foi criado no ano 1883 por meio de um decreto imperial (PREFEITURA MUNICIPAL DE NOSSA SENHORA DO LIVRAMENTO, 2016) e tem origens garimpeiras. Relata-se que, por volta de 1730, aventureiros paulistas descobriram grandes reservas auríferas à beira do Ribeirão dos Cocais e ali formaram um povoado, primeiramente chamado de São José dos Cocais. Segundo a Wikipédia (2016), Livramento, como é conhecido é um dos municípios mais antigos do Estado de Mato Grosso, e sua fundação é da época em que ocorreu o ciclo do ouro. Seu nome original era Cocais, em virtude da grande quantidade dessa vegetação em seu território. Atualmente, a economia do Município gira em torno da agricultura de subsistência ou pequena agricultura, como é chamada, da pecuária, com a criação de gado para produção de leite, recria e corte, da produção de banana, com industrialização, e da mineração.

O Município possui uma extensão de mais de $5.300 \mathrm{~km}$, e sua população tem diminuído nas últimas décadas, conforme dados do Instituto Brasileiro de Geografia e Estatística (IBGE) do ano 2010. No momento atual, estima-se que essa população seja em torno de 14.000 pessoas. Livramento faz parte dos municípios que compõem a Baixada Cuiabana ${ }^{4}$ e, conforme descrito na Wikipédia (2016), é um dos mais ricos em termos de acervo cultural do Mato Grosso, sendo a figura do pantaneiro parte do artefato cultural da região. De acordo com a Prefeitura Municipal de Nossa Senhora do Livramento (2016), a maioria das escolas municipais estão situadas no campo, totalizando 15 de ensino fundamental e duas instituições de educação infantil. As escolas estaduais seriam seis: quatro no campo e duas na cidade, mas, conforme as informações coletadas na Escola José de Lima Barros, focalizada neste artigo, no ano 2016, o campo passou a ter cinco instituições escolares estaduais.

Assim, a Escola José de Lima Barros, a qual pesquisamos, foi criada em 1989. De início, por nomeação, atuaram nela três professores, uma mulher e dois homens, sendo um destes o diretor. No ano 1993, ocorreu um concurso público, e, então, ingressaram outros dois professores, os quais são efetivos até os dias atuais. Nesse mesmo ano, na descrição do Projeto Político-Pedagógico (PPP 2015), surgiu uma das salas anexas, em razão da demanda que se apresentava.

\footnotetext{
${ }^{4}$ O Território Baixada Cuiabana, MT, abrange uma área de $85.369,70 \mathrm{Km}^{2}$ e é composto por 14 municípios: Acorizal, Barão de Melgaço, Campo Verde, Chapada dos Guimarães, Cuiabá, Jangada, Nobres, Nossa Senhora do Livramento, Nova Brasilândia, Poconé, Rosário Oeste, Santo Antônio do Leverger, Várzea Grande e Planalto da Serra. A população total do território é de 976.064 habitantes, dos quais 77.147 vivem na área rural, o que corresponde a 7,90\% do total. Possui 10.260 agricultores familiares, 11.154 famílias assentadas, 49 comunidades quilombolas e quatro terras indígenas. Seu IDH médio é 0,79 (BAIXADA CUIABANA, 2016).
} 
Na Escola sede, na qual desenvolvemos a pesquisa, há cerca de 100 alunos matriculados e um total de 11 docentes, dois vigias, duas funcionárias da limpeza e duas cozinheiras. Há sete turmas, sendo duas multisseriadas, uma dos anos iniciais e outra dos anos finais do ensino fundamental. Vinculadas a essa Escola, há outras 25 turmas em 17 salas anexas, localizadas em 16 comunidades, sendo a maioria de atendimento em Educação de Jovens e Adultos (EJA). As comunidades são as seguintes: Laginha e Cabocla, com quatro turmas cada, Rio dos Peixes e Coxos, duas turmas. Nas demais - Quilombo, Cristal, Chapadão, Figueiral, Cabeceira, Morro Cortado, São Manoel do Parí, Campinas de Baixo, Maciel, Cachoeirinha, Buriti do Atalho, Cumbarú e Buriti Grande -, há uma turma cada. Ao todo, são 40 professores vinculados à Escola, somados os que atuam nas salas anexas, e, desse total, apenas três são efetivos, sendo 37 contratados/interinos.

A metodologia utilizada para o desenvolvimento desta pesquisa foi a observação participante. Ezpeleta (1986, p. 83) trata a observação participante como uma técnica e afirma que ela "[...] possibilita formas de interação entre o pesquisador e os sujeitos, permitindo uma abordagem pessoal e abrindo fontes de informação como nenhuma outra." Descreve, ainda, que as interações de melhor proximidade com os sujeitos envolvidos na pesquisa permitirão construir circuitos de relações informativas potencializadoras na coleta de informações muitas vezes não acessíveis em espaços formais ou em documentos oficiais.

Desse modo, fazendo parte da observação participante, as reflexões apresentadas neste texto são oriundas de observações registradas em diário de campo, realizadas com docentes e funcionários nas diversas idas mensais e, por vezes, quinzenais à escola durante o segundo semestre de 2015 e o primeiro semestre de 2016. A essas observações, acrescentam-se entrevistas gravadas e transcritas com cinco docentes atuantes no ensino médio, o diretor e a coordenadora pedagógica, uma funcionária do setor de limpeza e outra da cozinha, seguindo um roteiro semiestruturado de questões.

Foram entrevistados, também, seis jovens do ensino médio. ${ }^{5} \mathrm{O}$ foco do nosso olhar, no entanto, esteve centrado nos saberes-fazeres que atravessam a Educação do Campo, podendo ser descritos, portanto, como os saberes das comunidades que são vivenciados no cotidiano da escola no processo de ensino-aprendizagem. Desse modo, as observações ocorreram sobre algumas aulas, sua metodologia e conteúdos, processo de participação da comunidade na escola, organização pedagógica

\footnotetext{
${ }^{5}$ Todos os docentes, assim como os funcionários e os alunos, assinaram o termo de consentimento livre e esclarecido. Os alunos menores de idade tiveram o referido termo assinado também pelos seus respectivos responsáveis, conforme as normas da ética na pesquisa.
} 
do trabalho dentro e fora das salas de aula e momentos informais de conversas com professores e educandos.

Na perspectiva de elucidar e problematizar os saberes-fazeres que podem interferir, ou não, na Educação do Campo, desde já pontuamos o fato de estarmos filiadas a uma concepção alargada de educação, nesse caso, a escolar. Como ressalta Brandão (1983, p. 7), educação “[...] para aprender, para ensinar para aprender-e-ensinar. Para saber, para fazer, para ser ou para conviver todos os dias, misturamos a vida com a educação.” Desse modo, consideramos saberes-conhecimentos sem estabelecer uma separação entre um e outro, como se um fosse do universo científico e o outro, popular, sem possibilidades de intercâmbio.

Além disso, reconhecemos haver o entrecruzamento de saberes dos tempos/espaços das vivências e experiências fora do universo escolar, que se tornam educativos e sistematizados no âmbito da escola por parte dos docentes em exercício. Do mesmo modo, há de se considerar que a escola possui a função de desenvolver um saber específico, caso contrário não teria sentido na sociedade. Contudo, esse saber específico não precisa negar ou desconsiderar outros saberes, que, por sua vez, traduzem-se em um saber-conhecimento integral/integralizado. Isso explica a expressão saberes-fazeres com a qual trabalhamos neste texto.

\section{SABERES-FAZERES COTIDIANOS NA ESCOLA DO CAMPO: ALGUMAS OBSERVAÇÕES}

A educação, de modo alargado, requer que se olhe muito além do espaço da escola e das práticas pedagógicas - normalmente entendidas como aquelas de sala de aula. Sobre essa concepção de educação, podemos buscar amparo em Freire (1987), quando este trata da educação como forma de intervenção no mundo, a qual vai além da transmissão de conhecimento. Nessa mesma direção, defendendo que as aprendizagens, mesmo escolares, ocorrem em consonância com o que ocorre na sociedade, Arroyo (2011, p. 145) argumenta que:

\begin{abstract}
As formas de conhecer, de apreender o conhecimento, tão centrais na pedagogia escolar, não são uma mera projeção das faculdades intelectuais separadas do mundo exterior. Nossos alunos não são espírito, inteligência, consciência que aprendem ou não isolados dos outros seres humanos, da condição corpórea e biológica, da produção material da existência. Prestar atenção a esse tecido social em que os indivíduos se formam ou deformam nos leva a uma visão mais rica e mais integrada do ser humano, de sua formação e da educação escolar. Enriquece a
\end{abstract}


teoria pedagógica porque recuperamos matrizes que são constitutivas.

Ao nos referirmos à educação e aos saberes-fazeres da/na Escola do campo José de Lima Barros, de Livramento, MT, precisamos considerar minimamente o contexto socioeducacional. Mato Grosso é considerado o estado do agronegócio, com grande destaque para os municípios da região Norte, como Sorriso, Lucas do Rio Verde, Sinop e Nova Mutum. Além disso, apresenta uma rica agrobiodiversidade (fauna, flora, biomas), bem como uma multiplicidade de povos, especialmente no que se refere ao campo e aos modos de vida no/do campo. Se há um contexto em que se destaca o agronegócio e, imbricado nele, os grandes latifúndios, há também outro contexto, o dos sem-terra ou mesmo da agricultura familiar/camponesa ou, ainda, da agricultura tradicional, no caso das populações quilombolas e povos indígenas.

Todavia, essa contradição que mostra a existência de latifúndios representativos do agronegócio, de um extremo, e de uma diversidade de povos que vivem do trabalho com a terra ou originários da terra, de outro, muitas vezes, passa despercebida e incide sobre os moldes de fazer, compreender e optar por políticas públicas de educação. Isso se confirma quando se toma conhecimento da riqueza anunciada pelas cifras do agronegócio, altamente financiado e subsidiado pelo Estado brasileiro (GUANZIROLI; BERENGER, 2010). E na contramão dessa riqueza, encontra-se a pobreza das populações tradicionais, inclusive indígenas e quilombolas, em luta constante pela defesa e manutenção de suas terras, em meio aos conflitos territoriais e por acesso à água, implicando a sua sobrevivência e a existência da sociobiodiversidade (SILVA; SATO, 2012). Desse modo, se observarmos os sites da Wikipédia e da Prefeitura Municipal, em se tratando da descrição do Município, constatam-se as origens garimpeiras, mas ambos anulam a existência de povos indígenas, em grande medida, dizimados, bem como dos negros escravizados e de seus descendentes.

Assim, há um Mato Grosso rico, mostrado e promovido pelas grandes empresas de comunicação, e outro pobre, ou empobrecido, grandemente culpabilizado nos conflitos sociais que aparecem para a sociedade, de uma maneira ou de outra. $\mathrm{O}$ que não se pode negar é, também, a riqueza da biodiversidade, uma beleza de encher os olhos, que, consequentemente, desperta a cobiça dos que pensam em transformar e sugar a natureza até o seu limite, para se beneficiar economicamente.

No dizer de Mello (2006), o Estado do Mato Grosso, analisado por muito tempo sob uma óptica desenvolvimentista (desde a década de 1940), era considerado um território a ser ocupado, pois de forma alguma eram consideradas as populações 
quilombolas e tampouco os povos indígenas nele existentes. Tanto é que houve planos políticos chamados de Integração Nacional, adotados no período da Ditadura -Militar, que se estendeu de 1964 a 1985, como se esse território não pertencesse ao Brasil e se tratasse mesmo de um espaço vazio.

Fazendo parte desse mesmo contexto emblemático e enfatizando que o território mato-grossense não pertence somente ao agronegócio, Silva e Sato (2012) apresentam uma pesquisa muito significativa com o mapeamento dos grupos sociais no Estado mato-grossense. As autoras conseguiram identificar a existência de 47 diferentes etnias indígenas e 99 identidades distintas de povos e populações. $\mathrm{Na}$ descrição das autoras, há povos pantaneiros, mimoseanos, morroquianos, beiradeiros, fronteiriços e ribeirinhos. Em relação ao tipo de trabalho, identificam-se: seringueiros, extrativistas, retireiros do Araguaia, artesãos, pescadores artesanais, agricultores familiares, articuladores da economia solidária, etc. Os povos indígenas totalizam cerca de 80 conhecidos, e cerca de sete ainda considerados isolados. Além disso, são 69 comunidades quilombolas.

A região em que está situada a Escola José de Lima Barros, na qual desenvolvemos a pesquisa, é considerada da Morraria, em razão da presença de morros, e, por assim dizer, local onde se refugiavam escravos formando quilombos, no período da escravidão. No momento atual, essa Escola recebe alunos descendentes dos remanescentes de quilombos, como os das comunidades de Capão Verde e Morro Cortado. Nessas duas comunidades, até o momento da pesquisa, havia salas anexas, mas, por falta de crianças e jovens para frequentar os cursos oferecidos, Capão Verde encerrou as atividades escolares em 2015.

Dos professores que tomaram parte na pesquisa, todos fizeram a sua formação universitária em faculdades particulares, em virtude de o acesso a elas ser mais fácil, ou seja, mais próximas do que as universidades públicas, no caso, a Universidade do Estado de Mato Grosso (Unemat), campus de Cáceres, ou mesmo a Universidade Federal do Mato Grosso (UFMT), campus de Cuiabá. Alguns deles ou fizeram alguma especialização ou estão fazendo, e em apenas um caso foi em Universidade pública, especificamente, na UFMT, em um curso de especialização em Educação do Campo, oferecido na modalidade a distância, no ano 2015. Segundo foi possível constatar nas falas dos profissionais entrevistados, pareceu-nos que a Universidade pública ainda é algo distante deles, em se tratando de perspectivas de acesso.

Diante dessa observação, poderíamos perguntar: por quê? Um dos fatores mencionados é a distância entre os Municípios de Livramento e Cáceres, local de existência de um campus da Unemat. Contudo, mais do que a distância, implican- 
do deslocamento, o principal fator é a sobrevivência durante a realização do curso, pois, no caso de realizarem cursos a distância, permaneceram aqueles que puderam se manter trabalhando na escola. Assim, o quesito qualidade do curso acaba não sendo mencionado, mas a possibilidade de concluir a graduação para a obtenção do diploma.

Em relação à formação acadêmico-profissional, Diniz-Pereira (2015) discorda da assim chamada formação inicial de professores e enfatiza que nos últimos tempos, no Brasil, têm aumentado muito os cursos aligeirados, semipresenciais ou a distância. Do mesmo modo, ou em sentido semelhante, conforme destaca o autor, nos Estados Unidos, houve um grande crescimento da certificação alternativa de professores, implicando desregulamentação de cursos e programas educacionais.

A partir dessas reflexões, e relacionando-as ao contexto da Escola e seus profissionais, pontuamos algumas questões: de um lado, não podemos culpabilizar os professores quando buscam formação acadêmica em cursos a distância, pois, mediante os relatos, o acesso a uma universidade pública parece ainda não pertencer ao universo deles, uma vez que precisariam deixar de trabalhar e, ao mesmo tempo, conseguir se sustentar economicamente em outra cidade. Nesse caso, é evidente a falta de uma política pública para a qualificação docente, ainda que a situação tenha melhorado um pouco nos últimos anos.

$\mathrm{Na}$ Escola pesquisada, percebe-se que a maioria dos profissionais busca alguma especialização nesse momento, e o elemento mais destacado é a soma de pontos no currículo, estipulada pela Secretaria de Estado de Educação (Seduc), exigência que ocorre no início de cada ano. Com esse elemento, não poderíamos deixar de destacar que, dos 11 docentes que atuam na Escola, apenas três são efetivos. Estes, por sua vez, têm atuado em cargos de gestão. Um atua na coordenação pedagógica, o outro na coordenação das 25 salas anexas, e o terceiro é responsável pelo Programa Mais Educação, do Governo Federal. O diretor, neste momento, é um técnico que antes atuava na Secretaria da Escola, sendo também o único funcionário técnico efetivo.

A situação das salas anexas dessa Escola é a mesma. Todos os professores e técnicos são contratados e, diante dessa instabilidade, por vezes, se veem obrigados a assumir salas longínquas de suas residências, visto que a Escola sede, a José de Lima Barros, possui salas anexas em um raio de $70 \mathrm{~km}$ de distância. Entretanto, a maioria fica entre 30 e $60 \mathrm{~km}$, com acesso a elas por meio de estradas não pavimentadas. Segundo relatos, há cinco ou seis anos não ocorrem concursos públicos na rede estadual de ensino do Estado do Mato Grosso. Informações obtidas da direção do Sindicato dos Trabalhadores do Ensino Público (Sintep) do Estado atualmente, mostram que o número de docentes na rede pública estadual é de aproximadamente 22.000, e destes, 
60\% são profissionais contratados. Em relação ao Município de Livramento, de acordo com as informações da assessoria pedagógica municipal, o número de professores contratados em 2016 foi de 145, ao passo que os efetivos são apenas 34 (informações verbais).

Dentre os cinco docentes atuantes em sala de aula os quais entrevistamos e conversamos, uma delas está trabalhando como interina há 20 e outra há 25 anos. Perguntado a uma delas porque tem sido interina durante todos esses anos, respondeu que fez três concursos e foi aprovada, no entanto não assumiu nenhum por motivos aparentemente bizarros: em dois deles, não ficou sabendo da convocação, pois, na Escola, é recente a comunicação por telefone, sendo ainda precária a rede de internet, e no terceiro, não chamaram as pessoas aprovadas. Sobre esse fato, Diniz-Pereira (2015) chama a atenção para o trabalho docente ou, mais propriamente, para a condição de trabalho que, por sua vez, está ligada à condição do ser docente.

O mesmo autor destaca a necessidade de boas condições para a atuação profissional do docente, quando, de outro modo, a sociedade o responsabiliza pelas mazelas da educação, inclusive, estando subentendida apenas a educação escolar e não a educação de forma abrangente. Afirma, ainda, que a ideia da urgência de maior investimento na educação é corrente no Brasil, de maneira generalizada. Mas dessa constatação, muito pouco tem se revertido em ações concretas. Nesse caso, bate-se na mesma tecla para desviar a atenção sobre a necessidade de mudanças políticas e econômicas no País.

Ao que percebemos e nos foi revelado nas conversas direcionadas com os docentes e funcionários, até então não havia profissionais de outros municípios que contassem pontos para conseguir trabalhar na Escola José de Lima Barros, em razão do difícil acesso, mas, neste momento, apresenta-se uma mudança. Embora profissionais da cidade somente possam contar pontos para atuar nessa Escola no caso de não haver pessoas interessadas do campo, a concorrência tem aumentado entre profissionais do campo, e, assim, quem tiver maior número de pontos é enviado à Escola. Nesse caso, é perceptível a instabilidade dos profissionais como um todo pelo fato de a maioria possuir vínculo como contratado e não como efetivo, causando rotatividade.

Segundo as normas da Seduc, ao que nos foi dito por uma funcionária, todos os profissionais devem desenvolver projetos em horário extraescolar, com alunos ou com a comunidade, durante um semestre, para contar pontos no currículo, mas, para ela, o impedimento é que a maioria dos estudantes retorna às suas casas de transporte escolar assim que terminam as aulas. Outro quesito que conta pontos para a 
contratação é a formação em nível superior e a pós-graduação, e este tem sido um dos motivos da procura daqueles cursos citados, em especial, na modalidade a distância.

Em relação ao público atendido pela Escola, de acordo com o projeto político-pedagógico (PPP) (2015, p. 15), consta o seguinte: “[...] atende educandos que vêm das diversas áreas em torno da unidade escolar, como: quilombo, áreas de comunidades tradicionais, ribeirinhos, filhos de trabalhadores braçais e outros." O que é perceptível, no que se refere ao contexto em que a Escola está inserida e faz acontecer um processo educacional, é o fato de que esta atende à diversidade no que se refere ao modo de produção na agricultura: os descendentes de quilombolas são considerados povos tradicionais, os ribeirinhos e demais agricultores sitiantes são chamados de agricultores familiares, e os filhos de trabalhadores braçais, aqueles oriundos de famílias que trabalham em fazendas, são denominados peões/agregados ou empregados rurais.

O PPP (2015, p. 16), quando se trata da questão pedagógica, enfatiza o seguinte:

[...] valorizar o que os educandos trazem para sala a sala de aula, conhecimentos, ideias e intuições construídas através das experiências que vivenciam em seu grupo social. A pluralidade de etnia da escola possibilita diferentes modos de vida. Por exemplo, os alunos chegam à sala de aula com diferentes ferramentas básicas para classificar, ordenar, quantificar e medir.

Pode-se observar nessa citação que, nessa Escola, busca-se valorizar as manifestações culturais dos sujeitos que a frequentam. Em diálogo com Brandão (1983, p. 9), podemos afirmar que a concepção de educação para a Escola, se posta em prática no que se refere aos saberes-fazeres, considera que “[...] não há uma forma única nem um único modelo de educação; a escola não é o único lugar aonde ela acontece e talvez nem seja o melhor; o ensino escolar não é a única prática e o professor profissional não é o seu único praticante.” Nessa mesma direção, Arroyo (2011, p. 146), ao tratar da pedagogia, a descreve como “[...] uma arte, uma ciência e uma prática inseparável do tecido social. Esta percepção pode ser uma luminosidade promissora para a teoria pedagógica e para sua renovação."

Para que ocorra o processamento de algum saber escolar, toda escola tem uma função a cumprir, que lhe é própria, e, para isso, o professor é a pessoa responsabilizada por fazer esse processo acontecer. No caso, ele é mediador, facilitador e, acima de tudo, conhecedor, embora isso não venha a significar que conheça tudo ou 
algo em sua totalidade. Charlot (2013, p. 109) descreve o professor como sendo aquela pessoa que "[...] aceita essa dinâmica, negocia, gere a contradição, não desiste de ensinar e, apesar de tudo, mas nem sempre, consegue formar os seus alunos." O autor diz mais: existem tensões inerentes ao ato de educar e ensinar. Vejamos:

Essa tensão entre construir saberes e herdar um patrimônio é inerente ao ato de ensinar, mas como já mencionado, a força da tensão e as formas que ela toma dependem das configurações sócio-históricas. [...] Ensinar é, ao mesmo tempo, mobilizar a atividade dos alunos para que construam saberes e transmitir-lhes um patrimônio de saberes sistematizados, legado pelas gerações anteriores de seres humanos. (CHARLOT, 2013, p. 114).

Para entendermos os saberes-fazeres escolares, uma das questões centrais de nossa pesquisa para com todos os docentes e demais funcionários, independente da função que ocupam, foi preciso buscar saber qual a concepção de Educação do Campo de cada um e cada uma. Além disso, procuramos desvelar como acontece a relação dos saberes oriundos das comunidades, trazidos pelos educandos, não apenas em decorrência da relação da Escola com o contexto no qual está inserida.

A respeito da primeira questão, percebemos que não se trata de uma mesma concepção política, no mesmo sentido dos Movimentos Sociais Populares. Trata-se de uma concepção que, portanto, não vincula a função da Escola com articulação aos Movimentos, tampouco há a preocupação com um projeto de sociedade, de desenvolvimento e de país, conforme descreve Caldart (2008).

A concepção de Educação do campo, segundo nos foi dito, é, acima de tudo, uma educação que valoriza as pessoas do campo, seus saberes, sua cultura como identidade própria. Na fala de um docente, a Escola mantém uma horta, um pomar e galinhas porque considera que isso é importante no processo educacional, sabendo que a sua identidade não se resume a esses fatores, mas eles são importantes na medida em que são trabalhados cotidianamente.

Na afirmação de um dos entrevistados, a Educação do campo - e aí estão os saberes-fazeres - requer que sejam trabalhadas as questões relacionadas ao campo, especialmente ao trabalho que as famílias desenvolvem e que é gerador de experiências e culturas, embora não haja livros específicos ${ }^{6}$ para os anos finais do Ensino Fundamental e para o Ensino Médio. Aparece com força, nessa concepção de educação da pessoa entrevistada, a troca de conhecimentos e a valorização dos conhecimentos

\footnotetext{
${ }^{6} \mathrm{Na}$ entrevista ficou evidenciado que o livro é um suporte, não se tratando de utilização como um material único. Seria um apoio, conforme o relato do entrevistado.
} 
provenientes das experiências de pessoas mais velhas da comunidade, que conhecem técnicas de trabalho na roça, uso das plantas medicinais, saberes sobre construções de casas e cercas para animais, considerando os períodos de seca e de chuva, característicos do clima no Mato Grosso.

É possível perceber, na concepção de Educação do campo expressa pelo entrevistado, uma confirmação do que é registrado na obra de Kolling, Nery e Molina (1999). Escola do campo, segundo a concepção do texto-base escrito por esses autores, no primeiro caderno da Coleção Por uma educação básica do campo, é assim expressa: “[...] não precisa ser uma escola agrícola, mas será necessariamente uma escola vinculada à cultura que se produz por meio de relações sociais mediadas pelo trabalho." (KOLLING; NERY; MOLINA, 1999, p. 37). Além disso, os autores enfatizam, no bojo da Educação do campo e da Escola do campo, que "[...] muitas dessas experiências [não formais] representam focos importantes de resistência e de recriação da cultura do campo, fundamentais na própria formulação de uma proposta de escola do campo.” (KOLLING; NERY; MOLINA, 1999, p. 26-27, grifo do autor).

A pesquisa nos mostrou que, por parte da Escola, faz-se o possível para possibilitar um ensino contextualizado, ultrapassando as fronteiras das salas de aula, quando, por exemplo, mesmo dentro dos limites financeiros, levam-se os estudantes para visitar agroindústrias de produtos artesanais da região. Estes também participam do encontro anual de Educação do campo, que ocorre em um município vizinho, enfatizando a troca de experiências e sublinhando a sua importância para a troca de conhecimentos, experiências e sementes crioulas entre os participantes. Apesar disso, foi feita a referência à saída de muitos jovens do campo, assim que formados no ensino médio, em busca de trabalho nos centros urbanos.

Em geral, os jovens vão à cidade mais próxima, Várzea Grande; a maioria deles trabalha em supermercados e, com raras exceções, conseguem algo no setor público. Os registros dos depoimentos colhidos evidenciaram que os mais dedicados procuram dar continuidade aos estudos em nível superior em faculdades privadas, com ajuda financeira dos pais, em razão da grande oferta nesse Município. Desse modo, as expectativas dos jovens parecem ser limitadas em relação a permanecer no campo, pelo fato de migrarem para a cidade, tentando lá se estabelecer, mesmo mantendo o vínculo com as suas comunidades de origem, visitando-as nos finais de semana. Como afirmou um jovem estudante (informação verbal), “[...] a cidade é boa para quem tem dinheiro para se divertir. Aqui na roça, a gente pode se divertir sem precisar dinheiro." Como relatam os estudantes e professores, o campo é um bom lugar de se viver, mas também é necessário ter uma renda mensal. 
O que se pode perceber nas observações, nas conversas e entrevistas com funcionários, sejam os que trabalham na vigilância, sejam as que trabalham na alimentação ou na limpeza, é que há uma integração interessante na dinâmica da Escola, tanto é que, nas falas das funcionárias, estas mostraram a preocupação com o pomar e com a horta e também mencionaram o horário que as crianças da Educação Infantil precisam levantar para chegar à Escola. Segundo uma entrevistada, há crianças pequenas que acordam às quatro horas da manhã para aguardar o transporte escolar - uma mesma condução que passa em um sentido e depois faz outra rota -; o mesmo ocorre ao término da aula, e, assim, uma turma permanece na Escola, esperando o transporte retornar para levar os estudantes de volta às suas casas.

Em relação aos saberes, todas as professoras mencionaram que trabalham bastante a partir da realidade dos alunos, e, nesse sentido, afirmou uma docente: "[...] valorizo o conhecimento informal dos alunos, a gente trabalha a partir do que os alunos conhecem, mas também não dá pra ficar só nisso, preparo também para o ENEM." Outra professora destacou que, nas comunidades, há saberes e mitos que os alunos aprendem com os pais, desde pequenos, e então ela procura trabalhar com esses saberes considerando as estórias/mitos, e mesmo que não acredite em todos, respeita-os. Narrou, na mesma ocasião, que na comunidade há muitas estórias da época em que vigorou o ciclo do ouro, e que as pessoas mais velhas afirmam ser verídicas.

O que mais demarca a concepção de Educação do campo, a partir das falas das entrevistas e também das conversas informais, é que o fato de todos se conhecerem e de os professores residirem na comunidade facilita aquilo que chamam de "contato direto". Nesse aspecto, afirmam os entrevistados que, na Escola, manter esse contato direto com os educandos e, respectivamente, com suas famílias é um fator positivo no ato de educar, ensinar e aprender. Pelo que sabem, nas escolas urbanas isso não é possível, e, por essa razão, há muitos problemas. Essa proximidade mantém um clima tranquilo, tanto é que o relato do atual diretor (que assumiu em 2016) enfatiza que em cinco anos em que está nessa Escola nunca presenciou ou soube de uma briga ocorrida entre estudantes.

Outra questão importante a destacar é que a ação pedagógica cotidiana dos docentes, em geral, é pensada de maneira coletiva e compartilhada em momentos de intervalo, antes e após as aulas, na sala dos professores. Há esse tempo em que as pessoas se encontram e conversam pelo fato de que ainda é possível haver relações de trabalho menos ditadas pelo ritmo do relógio. Além disso, a presença da comunidade

${ }^{7}$ Exame Nacional de Ensino Médio (ENEM). 
dos arredores, dos vizinhos da Escola sempre foi e é bem-vinda, e, desse modo, é possível a contribuição deles para com a instituição em alguns casos.

Perguntamos se na Escola há algum conflito entre os estudantes que são descendentes de quilombolas, agricultores familiares e filhos de peões de fazendas, em razão de algumas diferenças que possam existir entre eles. A resposta da coordenadora pedagógica enfatiza que não, e que fazem amizades indiferentemente das comunidades de origem. De um lado, percebemos que, de fato, há uma tranquilidade, o que se reflete também no respeito dos educandos para com os professores e demais funcionários e funcionárias da Instituição, mas, de outro, nos pareceu que, ao falarmos de conflito, soou como algo negativo, como se essa Escola não pudesse ser um lugar onde conflitos acontecem.

Sobre isso, Apple (2006, p. 130, grifo do autor) nos auxilia na reflexão, descrevendo que

Um pressuposto básico parece ser o de que o conflito entre grupos de pessoas é inerente e fundamentalmente mau, e devemos lutar para eliminá-lo dentro dos limites estabelecidos das instituições, em vez de ver o conflito e as contradições como a "força motriz" básica de uma sociedade.

A partir da argumentação do autor, ao que pudemos perceber durante os vários momentos em que estivemos na Escola, é que na cultura da Baixada Cuiabana, os conflitos são evitados, embora não deixem de existir. De alguma maneira, isso é positivo, porque mantém certa tranquilidade, porém, de outra, em não aparecendo os conflitos, ou mesmo não dando vasão a eles, como elementos pedagógicos, deixa-se de trabalhar questões que poderiam enriquecer e/ou problematizar ocorrências, as quais Freire (1987, p. 126, grifo do autor) identifica como situações limites, que, por sua vez, podem levar ao que esse educador entende como “inédito viável”.

Por isso é que, para nós, o "inédito viável” [que não poder ser apreendido no nível da "consciência real" ou efetiva] se concretiza na "ação editanda", cuja viabilidade antes não era percebida. Há uma relação entre o "inédito viável" e a "consciência real" e entre a "ação editanda" e a "consciência máxima possível".

$\mathrm{Na}$ realidade, os conflitos não têm aparecido como embates, e um dos fatores que suspeitamos ser o motivo é a religiosidade presente na Escola, bem como o parentesco entre muitos estudantes e professores. Isso, por sua vez, anula as possibilidades de os educadores trabalharem as contradições, de modo a trazerem para os 
espaços de aprendizagem oportunidades de debates sobre situações que se ocultam sob a aparente harmonia dos estudantes, professores e funcionários, incluindo, também, a comunidade.

\section{ALGUMAS CONSIDERAÇÕES PARA FINALIZAR}

Ao abordarmos saberes-fazeres que impregnam a relação entre os professores, educandos e, mesmo que indiretamente, as famílias das comunidades de uma Escola do campo, foram evidenciadas algumas questões que merecem continuar sendo pensadas e problematizadas na Educação do campo. Entretanto, há de se reconhecer o limite de uma pesquisa perante os inúmeros processos vivenciados e experienciados no cotidiano de uma escola.

Um primeiro elemento que fica exposto em nossa compreensão é que os profissionais daquela instituição educacional defendem a Educação do campo, e, ao mesmo tempo, ao fazerem o que podem enquanto professores, demonstram a limitação existente diante da saída da maioria dos jovens da roça para a cidade, em busca de trabalho remunerado. Nesse aspecto, fica evidente o desencontro entre o papel da escola do campo, de acordo com a concepção do Movimento em defesa da $\mathrm{EdoC}^{8}$ no Brasil, e o que vem ocorrendo nos arredores da Escola. Isso evidencia que as políticas sociais não são suficientes para manter os jovens com oportunidades de permanecerem no campo com dignidade.

De acordo com os gestores dessa Instituição, há compreensão de que o papel da Escola do campo seria, segundo captamos, o de preparar os jovens para poderem continuar vivendo e sobrevivendo com dignidade no campo. Mas, no que eles

\footnotetext{
8 Esse Movimento defende a permanência dos jovens e suas famílias no campo, vivendo com dignidade e, para isso, denuncia e combate as políticas contrárias à agricultura familiar camponesa, bem como reivindica políticas em favor dos trabalhadores do campo. Desde o ano 1997, com o Encontro Nacional dos Educadores da Reforma Agrária (ENERA), no âmbito do Movimento dos Trabalhadores Rurais sem Terra (MST), foi iniciado um movimento em favor e em luta pela defesa da Educação do campo, sendo esta explicitada e fortalecida em parâmetros político-institucionais na primeira Conferência Nacional de Educação do Campo, ocorrida em Luziânia (GO) em 1998. A partir desta, articula-se um movimento amplo denominado Movimento Por Uma Educação Básica do Campo no primeiro momento e, posteriormente, Movimento Por Uma educação do Campo, com o lançamento de vários subsídios teóricos. Esse Movimento contou, principalmente, com intelectuais orgânicos do MST e, somados a eles, muitos outros de organizações populares e sindicais, além de profissionais da área das ciências humanas e sociais de universidades e demais instituições educacionais, incluindo gestores municipais, estaduais e federais. Os primeiros materiais lançados, conhecidos como Cadernos de Formação, são do ano 1999. Além destes, em 2004, foi editado pela Editora Vozes um livro significativo escrito por intelectuais do Movimento. Em 2012, houve o lançamento do Dicionário da Educação do Campo com participação de 107 intelectuais e militantes brasileiros. Esse dicionário aborda 116 temas relacionados ao campo e totaliza 787 páginas, organizado por Roseli Salete Caldar, Isabel Brasil Pereira, Paulo Alentejano e Gaudêncio Frigotto.
} 
também percebem, não se trata somente de uma vontade ou de a escola cumprir seu papel, pois se esbarra em uma questão estrutural, que é a pouca ou a falta total de terra das famílias camponesas. Por outro lado, eles afirmam que os jovens precisam ter renda e buscar pelo seu espaço, não havendo muitas alternativas na própria comunidade.

Contudo, um elemento colocado pelos gestores, que foi também percebido por nós quando entrevistamos os discentes, é que há algumas perspectivas para aqueles jovens que dizem querer permanecer, porque já estão inseridos em atividades da agricultura familiar e quilombola em suas famílias. Nesse caso, são famílias que possuem terra própria, visto que uma parcela significativa de estudantes são filhos e filhas de peões de fazendas que trabalham com agropecuária. Nas entrevistas, os filhos de peões de fazenda afirmaram que ainda não sabiam o que fariam ao concluírem o Ensino Médio, enfatizando que o trabalho na lida com o gado, ajudando os pais, é muito duro, dando a entender que não queriam isso para si. Conforme ressalta Castro (2012, p. 441): “É evidente que os problemas enfrentados pelos jovens são antes de tudo problemas enfrentados pela pequena produção familiar, como as difíceis condições de vida e de produção."

Há receio, por parte dos professores, de que a Escola venha a ser fechada, pois na sede o número de estudantes vem diminuindo aos poucos. $\mathrm{O}$ que, de certa forma, ainda garante o não assédio direto para o fechamento dela são as salas anexas, cujo número de alunos tem aumentado nos últimos anos, em virtude da oferta da modalidade de EJA. Embora a Escola possua aproximadamente 100 alunos, de acordo com a atual coordenadora pedagógica, já foi ventilada a ideia de fechamento, tamanha é a pressão dos setores do agronegócio, inclusive influenciando diretamente o atual Governador do Estado do Mato Grosso e, por sua vez, a Seduc. Grosso modo, poderíamos afirmar que pensar em fechamento de uma Escola do campo com cerca de 100 alunos é um disparate em nome de economizar recursos, mas se a ideia já está ou esteve circulando significa que essa pressão já existe.

Transparece, assim, uma lacuna entre a vontade dos professores e, de certa maneira, uma defesa militante da Escola e da EdoC versus um contexto maior, inerente ao Estado do Mato Grosso e de sua opção político-administrativa em favor do agronegócio com o "esquecimento" do campo, que fica fora dos seus interesses político-econômicos. Rebuscando Frigotto (2011), diríamos que há necessidade de se considerar a reestruturação produtiva da globalização excludente, na dramática crise estrutural do trabalho. Por parte dos professores, parece que se preparam os alunos para um contexto no qual, em breve, eles serão expulsos ao final do Ensino Médio, com poucas exceções. Perguntados como fica a questão dos saberes específicos da 
EdoC que a Escola os prepara e potencializa em suas ações, nos foi respondido o seguinte: "Temos que ensinar tudo o que podemos sobre o campo, a valorização do campo, da agricultura familiar, da nossa cultura, do nosso valor para que saibam, mesmo que irão sair do campo [...] Porque um dia podem precisar." (informação verbal).

Os professores e funcionários compreendem essa situação-limite em que estão envolvidos; entretanto, ao que transparece nas entrevistas e observações, é uma torcida constante para que cheguem mais alunos em relação aos que saem. A questão política, no caso, envolvendo políticas de Estado favoráveis à agricultura familiar camponesa e quilombola, não é mencionada pelos docentes e gestores, assim como não aparece no PPP quando trata do contexto da Escola José de Lima Barros. Em nosso entendimento, essa é uma lacuna do ponto de vista político-pedagógico, pois ter/ manter ou não ter sujeitos no/do campo é uma questão de política de Estado, acima de tudo, e tem sido um ponto crucial para a EdoC.

Todos os professores entrevistados percebem que, apesar de seu esforço pessoal ao desenvolverem o trabalho pedagógico na perspectiva da EdoC, há uma situação das comunidades que "empurram" os jovens para fora, em busca de empregabilidade em troca de um salário. Diante dessa questão, os profissionais têm se debatido e se perguntado se o problema são eles, que não conseguem "passar" algo para que os jovens permaneçam no campo, o que evidencia a falta de uma relação mais ampla com as políticas estabelecidas para a juventude do campo. De outra maneira, nas falas, parece ficar explícito que os jovens precisam fazer seu futuro, mas ali a terra é pouca, e, em muitos casos, a terra é do patrão, e os jovens já pensam em ter um "destino" diferente dos seus pais, que é o de migrar de fazenda em fazenda em busca de trabalho (duro).

Logo, quando uma das docentes enfatiza: "Trabalho questões do campo, mas também preciso prepará-los para o ENEM", percebe-se a preocupação com a empregabilidade, ainda que precária, dos jovens. A atual coordenadora pedagógica, em uma das falas, deixa explícito que os jovens estudantes não têm nenhuma ilusão em relação à cidade; eles sabem que lá terão de enfrentar a vida dura, mas, se quiserem trabalhar para receber um salário, é isso que se apresenta. Outra professora deixa claro que é necessário gerar renda na agricultura familiar, e, assim, os jovens conseguem permanecer se quiserem, havendo essa opção pelo menos. Nesse sentido, é preciso mobilizar esforços para ir avançando nessa compreensão.

Em relação aos saberes e como eles ocorrem no contexto escolar, percebemos que, em grande parte, o processo de ensino é contextualizado incluindo a vida dos estudantes, dos próprios professores e da comunidade. Praticamente todos os discen- 
tes entrevistados citaram gostar das aulas de matemática, e, ao entrevistar também a professora dessa disciplina, percebemos que ela trabalha com questões da matemática utilizada na comunidade, como as medidas (braçadas ao invés de metros), construções de casas de barro que havia na comunidade e ainda há, mesmo que estejam desabitadas, contagem da banana por pares ao invés de quilos; ou seja, ela relaciona ao máximo o conteúdo trabalhado com a vida cotidiana, e isso faz com que os alunos participem e se sintam sujeitos. A professora disse que faz oito anos que veio da cidade para essa Escola e se deixou, primeiramente, aprender com os alunos e com a comunidade.

Com isso, precisamos romper com a concepção da escola "apenas" como um espaço para se ensinar. Temos que passar a enxergar esse espaço como local de produção de conhecimentos e saberes; um local onde identidades individuais e sociais são forjadas, onde se aprende a ser sujeito, cidadão crítico, participativo - atuante em sua comunidade - e responsável. (DINIZ-PEREIRA, 2015, p. 163).

Todos, alunos, funcionários técnicos e docentes, concordam que viver na comunidade rural é bom, é tranquilo, tem-se maior liberdade e segurança pelo fato de todos se conhecerem. O elemento confiança é muito importante no processo pedagógico, segundo pudemos captar, e ele parece ser próprio de alguns lugares do campo ainda existentes. O processo de ensino-aprendizagem foi bastante citado pelos discentes, como também as aulas de ciências agrárias, e as duas professoras que ministram essa disciplina.

Por parte dessas docentes, percebemos grande identificação com o tema, e por parte dos estudantes, além do interesse pelas coisas práticas que a aula proporciona e que eles também têm conhecimento em razão do contato com a natureza, eles enfatizam que as professoras falam a partir de suas experiências, ou seja, elas fazem aquilo que falam nas aulas, no campo da agroecologia e da diversidade.

Nesse aspecto, um elemento importante a ser citado é que há espaço na Instituição e nos seus arredores para o desenvolvimento de práticas associadas aos conhecimentos relacionados aos conteúdos abordados em sala de aula. Além disso, a comunidade é conhecida por todos e sempre contribui para aquilo que os estudantes e professores precisam e vice-versa. As pessoas da comunidade chegam sem receio à Escola e apresentam uma relação bastante familiar, o que é muito positivo do nosso ponto de vista. Parece não haver muro e grande distância entre comunidade e Escola, e este é um fator essencial no processo pedagógico, inclusive para a educação que se pretende diferenciada, como é a educação do campo. 
Um elemento aglutinador e que concede, aparentemente, unidade e não desavenças e conflitos na Escola é a valorização das tradições locais, no que se refere ao que é típico da Baixada Cuiabana, inclusive as festas de santos (São Gonçalo e São Sebastião). Na alimentação, as cozinheiras procuram, dentro do possível, preparar alimentos apreciados pelos alunos, valorizando aqueles de sua cultura, e, assim, ocorre uma grande interação com a comunidade escolar, pois as famílias se inserem na preparação de alimentos para as festividades e, por vezes, falam de seus conhecimentos tradicionais quando solicitados.

Essa unidade de ideias e práticas aparece, também, no aspecto de que o diretor e os demais coordenadores não estão separados cada um em sua sala, ainda que haja espaço físico para tal; eles preferem permanecer juntos, conseguindo, assim, dialogar e fazer os encaminhamentos de forma coletiva. No que se refere ao processo de ensino-aprendizagem, os professores relatam que é melhor e preferem permanecer em uma escola do campo, em razão de se conhecerem e poderem ter contato próximo uns com os outros, assim como com os estudantes e suas famílias. Em um dos depoimentos nos foi dito por uma professora: "[...] faço meu planejamento de atividades lá no saguão e, por vezes, nos intervalos, algum jovem ou alguma jovem pede para conversar comigo, desabafar sobre seus problemas.” (informação verbal).

Isso mostra que, nessa Escola (a José de Lima Barros), no Município conhecido como Livramento, MT, vive-se outro tempo, se for considerado o ritmo geral, próprio da sociedade capitalista, principalmente neste momento de crise. Ainda há tempo para diálogo e para a escuta entre colegas trabalhadores da Escola e destes com os educandos. Esse aspecto pode ser relacionado à qualidade da educação, no sentido de formação humana, conforme descrevem Freire (1999) e Arroyo (2002), sublinhando a humana docência na obra Ofício de mestre. Diniz-Pereira (2015), em seu estudo, afirma que as condições de trabalho, de modo geral, são piores nas escolas do campo, se comparadas às da cidade, e, assim, se olharmos para a Escola sede que pesquisamos, podemos discordar, mas isso não significa que esta seja a situação geral das escolas do campo e mesmo das salas anexas ligadas a ela.

Ao que pudemos perceber, e que é enfatizado por docentes e discentes, o clima de segurança, confiança e tranquilidade na Escola do campo é o ponto alto que é necessário considerar quando se analisa, no caso, o processo de relação entre saberes-conhecimentos. De outra maneira, a formação continuada de professores ocorre, principalmente, pela sala do educador, perfazendo 80h/ano. Como a formação acadêmico-profissional de todos foi realizada em instituições particulares, e, com uma exceção, todas foram na modalidade semipresencial ou a distância, inclusive as pós- 
-graduações, os professores apostam muito e ressaltam o saber de suas experiências ou, seguindo o título deste artigo, os saberes-fazeres.

Os saberes da experiência adquirida na prática pedagógica são de extrema relevância, mas nem por isso se deve abdicar de uma formação teórico-metodológica, inclusive, referente à especificidade da $\mathrm{EdoC}$, para que se consiga superar ou ir além dos esforços individuais de cada profissional, sem eximir os esforços e investimentos do poder público. Por fim, outra questão que merece destaque em relação aos saberes e fazeres, é que, desde nossa percepção, segundo a pesquisa, é necessário o Estado estabelecer concursos públicos para elevar o número de concursados e diminuir o número de interinos, pois a situação de interinidade e, por sua vez, de rotatividade gera insegurança, além de dificultar a inserção dos profissionais de fato na Instituição.

Acima de tudo, quando refletimos sobre os problemas da Escola de forma geral, conforme argumenta Diniz-Pereira (2015), os professores são os primeiros apontados como aqueles que não sabem ensinar ou fazer educação de qualidade; contudo, é preciso perceber também a gama de situações que os têm limitado para uma atuação qualificada, ainda que, a um olhar dialético, isso não possa ser entendido como desculpa para o não fazer ou o fazer de qualquer maneira.

\section{REFERÊNCIAS}

APPLE, M. Ideologia e currículo. 3. ed. Tradução Vinicius Figueira. Porto Alegre: Artmed, 2006.

ARROYO, M. Educação e teoria pedagógica. In: FRIGOTTO, G. (Org.). Educação e crise do trabalho: perspectivas de final de século. Petrópolis: Vozes, 2011. p. 138165.

ARROYO, M. Ofício de mestre. Imagens e auto-imagens. Petrópolis: Vozes, 2002.

BAIXADA CUIABANA. O território. Disponível em: <http://www.territoriosdacidadania.gov.br/dotlrn/clubs/territriosrurais/baixadacuiabanamt/one-community?page_num=0>. Acesso em: 07 nov. 2016.

BRANDÃO, C. R. O que é educação. 8. ed. São Paulo: Brasiliense, 1983.

CALDART, R. S. Sobre educação do campo. In: SANTOS, C. A. dos (Org.). Por uma educação do campo. Campo - políticas públicas - educação. Brasília, DF: INCRA/MDA, 2008. p. 67-86. 
CASTRO, E. G. de. Juventude do campo. In: CALDART, R. S. et al. (Org.). Dicionário da educação do campo. São Paulo: Expressão Popular; Rio de Janeiro: Escola Politécnica de Saúde Joaquim Venâncio, 2012. p. 437-443.

CHARLOT, B. Da relação com o saber às práticas educativas. São Paulo: Cortez, 2013.

DINIZ-PEREIRA, J. E. Formação de professores, trabalho e saberes docentes. Trabalho \& Educação, Belo Horizonte, v. 24, n. 3, p. 159-168, set./dez. 2015.

EZPELETA, J. Notas sobre pesquisa participante e construção teórica. In: EZPELETA, J.; ROCKWELL, E. (Org.). Pesquisa participante. São Paulo: Cortez; Autores Associados, 1986. p. 77-93.

FREIRE, P. Educação como prática da liberdade. 23. ed. São Paulo: Paz e Terra, 1999.

FREIRE, P. Pedagogia do Oprimido. 17. ed. Rio de Janeiro: Paz e Terra, 1987.

FRIGOTTO, G. Educação, crise do trabalho assalariado e do desenvolvimento: teorias em conflito. In: FRIGOTTO, G. (Org.). Educação e crise do trabalho: perspectivas de final de século. Petrópolis: Vozes, 2011. p. 25-54.

GUANZIROLI, C.; BERENGER, M. O. Experiências bem-sucedidas em agronegócio no Brasil e desenvolvimento sustentável. Brasília, DF: IICA, 2010.

KOLling, E. J.; NERY, I. I. J.; MOLINA, M. C. (Org.). Por uma educação básica do campo. 3. ed. Brasília, DF: Ed. UnB, 1999.

MELlO, N. A. de. Políticas territoriais na Amazônia. São Paulo: Annablume, 2006.

PREFEITURA MUNICIPAL DE NOSSA SENHORA DO LIVRAMENTO. Livramento tem origens garimpeiras. Disponível em: $<$ http://www.nossasenhoradolivramento.mt.gov.br/index.php?sid=183>. Acesso em: 09 fev. 2016.

PROJETO POLÍTICO-PEDAGÓGICO. Escola José de Lima Barros. Nossa Senhora do Livramento, 2015.

SILVA, R.; SATO, M. Mapa social. Mapeando os grupos sociais do Estado de Mato Grosso - Brasil. Cuiabá: Ed. UFMT, 2012.

WIKIPÉDIA. Nossa Senhora do Livramento. Disponível em: <http://pt.wikipedia. org/wiki/Nossa_Senhora_do_Livramento_\%28Mato_Grosso\%29>. Acesso em: 07 nov. 2016. 
Isaura Isabel Conte, Marlene Ribeiro

Recebido em 16 de julho de 2016 Aceito em 08 de novembro de 2016

Endereço para correspondência: Rua Anita Garibaldi, 416, Bairro Bela Vista, 78575000, Juara, Mato Grosso, Brasil; isauraconte@yahoo.com.br 